\title{
The Effect of Teaching Critical Thinking Skills on the De- cision Making Style of Nursing Managers
}

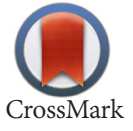

Zahra Kashaninia $^{1}$, Fateme Yusliani2 ${ }^{*}$, Mohammad Ali Hosseini ${ }^{3}$, Pouria Reza Soltani ${ }^{4}$

1. Department of Nursing, School of Nursing and Midwifery, Iran University of Medical Sciences, Tehran, Iran.

2. Department of Nursing, University of Social Welfare and Rehabilitation Sciences, Tehran, Iran.

3. Department of Rehabmanagment, University of Social Welfare and Rehabilitation Sciences, Tehran, Iran.

4. Department of Statistics, University of Social Welfare and Rehabilitation Sciences, Tehran, Iran.

ditation: Kashaninia, Z, Hosseini, MA \& Yusliani, F 2016, 'The effect of teaching critical thinking skills on the decision making style of nursing managers', Journal of Client-Centered Nursing Care, vol 1, no. 4, pp. 197-204.

dol: $:$ http://dx.doi.org/10.15412/J.JCCNC.04010405

Article info:

Received: 01 Jun. 2015

Accepted: 15 Sep. 2015
Keywords:

Critical thinking,

Decision making style,

Nurse administrator

\section{A B S T RA C T}

Background: One of the main goals of nursing education is training them to provide proper medical services to patients as well as healthy people in the community and health centers using their knowledge and specific skills. This service requires nurses' critical thinking and effective learning. The purpose of this study was to determine the impact of critical thinking skills on decision making styles of nursing management.

Methods: This interventional study is of semi-experimental kind and conducted on 60 nursing managers (30 in each group of the samples). In the beginning of the study, California questionnaire of critical thinking scale was completed by the participants. The intervention group received critical thinking skills training for 8 sessions (4 theoretical sessions and 4 practical sessions). A week after the end of the last training session, the same questionnaires were completed by the participants.

Results: Prior to conducting the study, 2 groups were not significantly different regarding demographic variables. The mean score of critical thinking and decision making style of the control group was the same before and after intervention, but in the intervention group, the mean score increased.

Conclusion: Teaching critical thinking skills increases the level of critical thinking and the use of rational decision making style by nurses. Nurses' cognitive ability, especially their ability to process information and make decisions, is a major component of their performance and requires possession of critical thinking. Thus, universities of medical sciences are suggested to provide necessary support to allow the development of professional competencies, decision making, problem-solving, and selfsufficiency skills, which are influenced by the ability for critical thinking.

\section{Background}

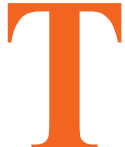

he English word "critical thinking" is derived from the Greek word "critidous" meaning "question", which indicates the ability to ana- lyze. Halpern considers critical thinking to be the proper use of cognitive skills that increase the possibility of achieving suitable results (Halpern, Roediger \& Stermberg 2007). Levy considers critical thinking a systematic and active cognitive strategy, which is necessary for examining, studying,

\section{* Corresponding Author:}

Fateme Yusliani, MSc.

Address: Department of Nursing, University of Social Welfare and Rehabilitation Sciences, Tehran, Iran.

Tel: +98 (912) 7782725

E-mail:fyousel@yahoo.com 
and understanding issues, solving problems, and decision making based on accurate reasons and valid evidence (Mazloomi, Naderian \& Nahangi 2012). People must have the ability to analyze, assess, and judge the conditions of their lives in order to make important decisions. Critical thinking ability and skill allows the person to process the surrounding information, infer objectively, assess problems concretely, and make conclusions based on various types of information (Hosseini \& Hosseini 2011; Neyestani \& Emamverdi 2011).

In the discipline of nursing, critical thinking; as a vital component of performance, communication, problem-solving, and theoretical and conceptual understanding of task; constitutes the basic knowledge of this science. Accordingly, the professional nurses are expected to exhibit this type of thinking, which is considered a fundamental component of training, in the clinical environment (Nafeei 2007).

Nowadays, in the field of medical healthcare, nurses are facing with increasingly complex problems, which making decisions about them requires their critical thinking. Critical thinking increases the decision making ability of the nurses regarding the identification of patient's needs and the choice of the best nursing procedures (Sarhangi et al. 2010). In other words, decision making always includes assessment and selection of one solution out of multiple solutions, each of them seems to be appropriate under certain circumstances (Alwani 2006).

There are 5 styles of decision-making, i.e. rational, intuitive, dependent, spontaneous, and avoidant styles. In the rational decision making style, a person is aware of all the solutions and knows the outcome of each decision and can arrange and organize the results of decision making in terms of priority (maximum benefit). Intuitive decision making style is the process of subconscious decision making, which is the result of gathered experiences. In the dependent decision making style, decision maker relies on the beliefs of others and has a passive role. Spontaneous decision making style suggests urgent conditions under which a person makes an immediate decision within minimum time without premeditation. In the avoidant decision making process, decision maker tends to avoid making any decisions as much as possible (Hadizadeh Moghaddam \& Tehrani 2009).

Marilan in his definition of critical thinking in nursing wrote: "Critical thinking is a rational and inferential thinking about nursing problems (nursing diagnosis) with more than one solution". It helps us make proper decisions under conditions where our belief and performance are different. He believed that critical thinking helps nurses make right decisions and judgments about the problems and issues related to the patients (Babamohammadi \& Khalili 2004).

Critical thinking enables nurses to assess necessary information in critical conditions and differentiate between problems that require immediate measures and those do not, and by considering the possible results of each measure, make right decisions (Eslami Akbar \& Moarefi 2010).

Nurses are important members of the healthcare system. Their knowledge, and skills can play a significant role in providing proper service to the patients (Alimohammadi \& Dadkhah 2005).

Teaching medical and paramedical disciplines is one of the areas in which the authorities try hard to improve its quality. Furthermore, they consider critical thinking skills necessary to understand the disciplines of medical sciences (Gharib et al. 2009).

Today, many authors have stressed the nurses' need for critical thinking to use appropriate information and skilled decisions in providing care to patients. They believe that learning critical thinking skills is essential in making decisions for the nurses and their future profession (Lotfi, Hasankhani \& Mokhtari 2010).

Critical thinking is so important that American Nurses Association considers it a compulsory criterion for faculties of nursing to grant degrees (Akhondzadeh, Ahmari Tehran \& Abedini 2011).

The nurses' ability of critical thinking can directly affect patient's safety. Nurses should be able to detect changes in the patient's condition and carry out nursing interventions, anticipate, and precede the orders. This function requires the ability to think critically, solve problems, and communicate effectively (Fero et al. 2009).

Research has shown that about 4\%-16.6\% of patients admitted to hospitals in America, Australia, and Britain are permanently disabled or die due to errors of nurses and healthcare personnel, resulting from lack of appropriate decisions. However, a significant percentage of these damages are preventable (Paryad et al. 2011).

In the study by Javadi et al. aimed at determining the relationship between critical thinking and clinical decision of senior students of nursing at the School of Nursing and Midwifery, Guilan University of Medical Sciences, it was found that the majority of research participants $(86 \%)$ had poor critical thinking (Paryad et al. 2011). The studies also showed that the majority of students $(70 \%)$ had sys- 
tematic analytical decision-making, 30\% had analyticalintuitive decision making, and none of them had intuitiveinterpretive decision making.

The results of a quasi-experimental pretest/posttest study conducted by Moatari et al. (2002) in Tabriz entitled "The Impact of Rethinking on Critical Thinking Skills of Nursing Students" show that the experimental group achieved a significant positive change in the field of inductive reasoning and total score of California critical thinking skills compared to before the intervention. Also, the difference of the means of both groups before and after the intervention using t-test confirmed an increase in the scores of the experimental group as compared to the control group $(\mathrm{P}=0.03)$ (Moattari et al. 2002).

\section{Materials \& Methods}

This study is a quasi-experimental intervention. The main hypothesis of the research was that teaching critical thinking skills increases the use of rational decision-making style by nurse managers. The research population consisted of Mofarah Hospital nursing managers. After obtaining permission from Tehran University of Welfare and Rehabilitation Sciences and obtaining informed consents from the participants, the study sample were selected using census method. The sample size in each group was $30(\mathrm{n}=60)$. The inclusion criteria were having undergraduate or graduate degree in nursing, working in organizational posts as matron, supervisor, head nurse, or shift supervisor, willing to participate, and being physically and mentally prepared to answer the questions. Exclusion criteria consisted of retirement during the intervention, change of the workplace, withdrawal of the subjects from the study, incomplete response to questionnaires, or returning them during the study.

Each subject was randomly assigned into 2 groups of control and intervention using simple random sampling method. Setting of the study was Mofarah Hospital in Tehran. All participants were allowed to leave the study at any stage. By assigning a code to each participant, anonymity was taken into consideration. The intervention group received critical thinking skills training for 8 sessions (4 theoretical sessions and 4 practical sessions).

In the first 4 sessions, the theoretical foundation (extracted from books and databases) was taught to participants. It comprised generalities, definitions and concepts, principles and skills of critical thinking, objectives, features and indicators, its importance, advantages, and applications of these skills, obstacles and challenges and the strategies to achieve these skills and how to promote them. Presentation of theoretical material was in the lecture format, using educational tools, and question and answer sessions. At the end of the session, the participants were asked to list 5 issues that required decision making for the next session.

In the fifth session, after group study and scoring the participants, the most important problem was selected and clarified. At the end of the session, participants were divided into 6 groups of 5 and were asked to gather information for the next session and analyze the problem and list its causes. In the sixth session, after the presentation of the causes, through group discussion, the most important cause was chosen and the participants were asked to consider the limitations, resources, time, and executive facilities to determine 3 solutions. In the seventh session, after assessment of the advantages and disadvantages of solutions, the best solution was selected. Selected solution was practically used for 2 weeks in units. In the eighth session, performance was evaluated using a checklist. Finally, a week after the intervention, posttest was taken from both groups.

Data were collected using 1) A demographic information questionnaire, 2) The standard California Questionnaire of Critical Thinking Skills Test; Form B (CCTSD), and 3) General decision-making styles questionnaire before and after intervention. All questionnaires were completed by participants in the research. To assess the critical thinking skills, CCTSD was used. This test includes 34 multiple choice questions and 5 subtests of analysis, inference, evaluation, inductive reasoning, and deductive reasoning. It takes 45 minutes to answer the questionnaire. One point is awarded for each correct answer.

Test respondents can receive a score between 0 and 34 . Score 16 or higher indicates strong critical thinking and lower than that indicates poor critical thinking. Decision making style questionnaire is a self-report tool which has 25 statements. The subject should express his or her agreement or disagreement with any of the statements using a 5-point Likert-type scale (1=strongly disagree to $5=$ strongly agree). By comparing the scores of the subject in the subscales of diverse styles, his or her main style is identified. The subscale that has the highest score is the dominant style of the participant in decision-making. To obtain the score of each subscale, it is enough to add up the scores of all the statements related to that subscale.

Statements related to each subscale are as follows

- Avoidant style: 6, 14, 19, 21, and 23;

- Spontaneous style: 8, 9, 15, 20, and 24;

- Dependent style: 2, 5, 10, and 22; 
- Intuitive style: $1,3,12,16$, and 17;

- Rational style: 4, 7, 11, 13, and 25 .

CCTSD has strong content validity because it has been presented based on the definition of critical thinking and developed by American Association of Philosophy and the University of California. Facione and Facione have reported the reliability of this test between 78.0 and 80.0 by using the Kuder-Richardson Formula 20. Khalili has also reported the reliability of CCTSD as 62.0.

Formal and content validity of this questionnaire was examined by the faculty of Social Welfare and Rehabilitation Sciences and Tarbiat Modarres universities, Tehran, Iran. After making the necessary changes, the questionnaire was distributed among 20 nurses to determine the reliability of the questionnaire. As a result, the Cronbach Coefficient $\alpha$ was calculated as 63.0

Statistical analysis was performed using SPSS-16. Indices such as frequency, mean and standard deviation were calculated regarding descriptive statistics. Owning to census sampling, the means and their differences were used to compare the intervention and control groups.

\section{Results}

Sixty nurses working at Mofarah Hospital were randomly assigned to the intervention and control group. In this study, there was no drop in subjects. The mean (SD) age of the intervention and control group were 37.60 (6.27) and 38.30 (6.99) years, respectively (Table 1). In the intervention group, $80 \%(\mathrm{n}=24)$ of the participants were female and $20 \%(n=6)$ were male and in the control group,
$76.6 \%(n=23)$ were female and $23.3 \%(n=7)$ were male. The Chi-square test for both groups showed that there was not a significant difference between 2 groups regarding demographic characteristics.

The results showed no relationship between age and style of decision-making, nor between age and critical thinking. There is also no difference between 2 sexes with regard to the style of decision making and critical thinking (Table 7). Comparison of the 2 groups of holders of bachelors and masters degrees with regard to the style of decision making and critical thinking showed no difference (Table 6); however, people with master's degree have a higher critical thinking skills. Comparison of the style of decision making and critical thinking in groups with different work experience showed that only decision making style was associated with work experience and those who had work experience of 6-10 years had a higher score of rational decision making style (Table 4, 5).

The results showed that the difference between the mean score of rational decision making style in the intervention group increased by 3.1 (Table 2) while in the control group it increased by 0.5 (Table 3 ) that reflects the positive impact of training. The results showed that the mean score of critical thinking in the intervention group increased by 4.03 after the intervention which is due to the training (Table 4).

\section{Discussion}

In the present research, the impact of critical thinking skills on decision making styles of nursing managers at Mofarah Hospital was studied. The results showed that this training leads to increased use of rational decision making style as well as higher critical thinking score. In Zahednejad

Table 1. Comparison of age between 2 groups.

\begin{tabular}{|c|c|c|c|}
\hline & Group & Mean & SD \\
\hline \multirow{2}{*}{ Age, Y } & Intervention & 37.60 & 6.27 \\
\cline { 2 - 4 } & Control & 38.50 & 6.99 \\
\hline
\end{tabular}

Client-Centered Nursing Care

Table 2. Comparison of the mean and difference of decision making style scores in the intervention group before and after intervention.

\begin{tabular}{|c|c|c|c|}
\hline Decision making style & Mean score before intervention & Mean score after intervention & 10.53 \\
\hline Avoidant & 12.46 & 10.40 & -1.93 \\
\hline Spontaneous & 11.06 & 17.20 & -0.66 \\
\hline Dependent & 15.50 & 15.63 & -2.99 \\
\hline Intuitive & 18.35 & 22.20 & 3.1 \\
\hline Rational & 19.10 & & 20 \\
\hline
\end{tabular}


Table 3. Comparison of the mean and difference of decision making style scores in the control group before and after intervention.

\begin{tabular}{|c|c|c|c|}
\hline Decision making style & Mean score before intervention & Mean score after intervention & Difference \\
\hline Avoidant & 10.30 & 10.13 & -0.17 \\
\hline Spontaneous & 10.93 & 11.66 & 0.73 \\
\hline Dependent & 14.23 & 16.70 & 2.47 \\
\hline Intuitive & 17.56 & 16.10 & -1.46 \\
\hline Rational & 18.60 & 19.10 & 0.5 \\
\hline
\end{tabular}

Table 4. Comparison of the mean and difference of critical thinking scores in the intervention group before and after intervention.

\begin{tabular}{|c|c|c|c|}
\hline Aspects of critical thinking & Mean score before intervention & Mean score after intervention & Difference \\
\hline Analysis & 2.66 & 3.76 & 1.1 \\
\hline Evaluative & 5.03 & 5.60 & 0.57 \\
\hline Inference & 4.10 & 4.70 & 0.6 \\
\hline inductive reasoning & 6.06 & 7.33 & 0.27 \\
\hline deductive reasoning & 4.73 & 5.23 & 4.03 \\
\hline Total score & 22.60 & 26.63 & 0.5 \\
\hline
\end{tabular}

Client-Centered Nursing Care

Table 5. Comparison of the mean and difference of the mean scores of critical thinking in the control group before and after intervention.

\begin{tabular}{|c|c|c|c|}
\hline Aspects of critical thinking & Mean score before intervention & Mean score after intervention & Difference \\
\hline Analysis & 3.03 & 2.70 & 0.33 \\
\hline Evaluative & 4.33 & 5 & 0.67 \\
\hline Inference & 2.93 & 3.73 & 0.8 \\
\hline inductive reasoning & 5.83 & 5.80 & -0.03 \\
\hline deductive reasoning & 3.60 & 4.50 & 0.9 \\
\hline Total score & 19.73 & 21.73 & 2 \\
\hline
\end{tabular}

Client-Centered Nursing Car

Table 6. Comparison of the mean and difference in the score of decision-making style between the two groups of bachelor's degree and master's degree.

\begin{tabular}{|c|c|c|c|}
\hline Variable & Degree & Mean & Difference of the two means \\
\hline \multirow{2}{*}{ Avoidant style } & BS & 11.61 & \multirow{2}{*}{1.74} \\
\hline & MS & 9.87 & \\
\hline \multirow{2}{*}{ Spontaneous style } & BS & 10.82 & \multirow{2}{*}{1.3} \\
\hline & MS & 12.12 & \\
\hline \multirow{2}{*}{ Dependent style } & BS & 15.03 & \multirow{2}{*}{1.28} \\
\hline & MS & 13.75 & \\
\hline \multirow{2}{*}{ Intuitive style } & BS & 18.25 & \multirow{2}{*}{1.50} \\
\hline & MS & 16.75 & \\
\hline \multirow{2}{*}{ Rational style } & BS & 18.90 & \multirow{2}{*}{0.40} \\
\hline & MS & 18.50 & \\
\hline \multirow{2}{*}{ Critical thinking } & BS & 20.40 & \multirow{2}{*}{5.72} \\
\hline & MS & 26.12 & \\
\hline
\end{tabular}


Table 7. Correlation of the age and style of decision making and critical thinking.

\begin{tabular}{|c|c|c|c|c|c|c|}
\hline & Age & Avoidant style & $\begin{array}{c}\text { Spontaneous } \\
\text { style }\end{array}$ & $\begin{array}{c}\text { Dependent } \\
\text { style }\end{array}$ & Intuitive style & Rational style \\
\hline Avoidant style & 0.03 & & & & & \\
\hline Spontaneous style & 0.03 & 0.29 & & & & \\
\hline Dependent style & 0.07 & 0.43 & 0.14 & & & \\
\hline Intuitive style & 0.12 & 0.16 & 0.26 & 0.001 & & \\
\hline Rational style & 0.08 & -0.04 & -0.04 & -0.05 & 0.06 & -0.02 \\
\hline Critical thinking & 0.09 & 0.15 & 0.01 & 0.03 & 0.02 & \\
\hline
\end{tabular}

study, the impact of an active training method on critical thinking of nursing students in Lorestan Province, Iran was studied that led to an increase in their critical thinking score, which is consistent with the results of the present research.

Paryad et al. (2011) conducted a descriptive-correlational study entitled "The Relationship between Critical Thinking and Clinical Decision of Students of Nursing at Guilan University of Medical Sciences", on 50 senior nursing students. The results showed that the majority of the studied subjects $(64 \%)$ had an average score (first through seventh semester) of 14-17 and work experience. The majority of students $(90 \%)$ had no experience of encounter with patients who had undergone Billroth 2 surgery in family and had the experience of encounter with patients during internship (90\%). Regarding critical thinking score, the majority of subjects $(86 \%)$ had weak critical thinking.

Regarding the scores of the subjects for the components of critical thinking, the results showed that the highest mean score of subjects belonged to deductive reasoning, and then to inductive reasoning, evaluation, inference, and analysis. In addition, results of the research regarding clinical decision making score showed that the majority of the subjects $(88 \%)$ had a proper decision making. Results of the research regarding the relationship between demographic characteristics and critical thinking score indicated that there was only a significant relationship between the critical thinking score and the mean average of previous semesters $(\mathrm{P}=0.001)$.

In addition, results showed no significant relationship between critical thinking score and clinical decision making. However, in the present study there was a relationship between critical thinking score and decision making style.

In conclusion, results of the research indicated that the score of rational decision making style increased in the posttest. Therefore, teaching critical thinking skills increases the use of rational decision making style by the nursing managers. Nurses' cognitive ability, especially their ability to process information and make decisions, is a major component of their performance and requires possession of critical thinking. Thus, universities of medical sciences must provide necessary support in order to allow the development of professional competencies, and decision making, problem-solving, and self-sufficiency skills, which are influenced by the ability for critical thinking. Because, this issue is important for nursesust provide necessary support and decision making, problem-solving managers. Nurseis recommended in this regard and the effective factors and strategies for improving critical thinking and directing nurses towards rational decision making must be investigated.

\section{Conflict of Interests}

The authors declared no conflict of interests.

\section{Acknowledgements}

We would like to appreciate the efforts of all those who assisted us throughout this research.

\section{References}

Akhondzadeh, K, Ahmari Tehran, H \& Abedini, Z 2011, '[Critical thinking in nursing education in Iran (Persian)', Iranian Journal of Medical Education, vol. 11, no. 3, pp. 210-221.

Alimohammadi, M \& Dadkhah, B 2005, ‘Continuous Medical Education from View of Nursing Personnel Working in Ardabil Hospitals (Persian)]', Journal of Ardabil University of Medical Sciences, vol. 5, no. 3, pp. 271-277.

Alwani, M 2006, [General management (Persian)], Ney Publication, Tehran.

Babamohammadi, H \& Khalili, H 2004, '[Critical thinking skills of Nursing Students in Semnan University of Medical Sciences (Persian)]', Iranian Journal of Medical Education, vol. 4, no. 2, pp. 23-31.

Eslami Akbar, R \& Moarefi, F 2010, ‘[A comparison of the critical thinking ability in the first and last term baccalaureate students of nursing and clinical nurses of Jahrom University of Medical 
Sciences in 2007 (Persian)]'. Journal of Jahrom University of Medical Science, vol. 8, no. 1, pp. 37-45.

Fero, L, Witsberger, C, Wesmiller, S, Zullo, T \& Hoffman, L 2009, 'Critical thinking ability of new graduate and wxperienced nurses', Advance Nursing, vol. 65, no. 11, pp. 139-148.

Gharib, M, Rabieyan, M, Salsali, M, Hajizade, E, Saborikashani, A, Khalkhali, H et al 2009, '[Critical Thinking Skills and Critical Thinking Dispositions in Freshmen and Senior Students of Health Care Management (Persian)]', Iranian Journal of Medical Education, vo. 9, no. 2, pp. 125-135.

Hadizadeh Moghaddam, A \& Tehrani, M 2009, '[A Study of The Relationship Between General Decision Making Styles Of Managers in Public Organization (Persian)]', Journal of Public Administration, vol. 1, no. 1, pp. 123-138.

Halpern, DF, Roediger, HL \& Stermberg, RJ 2007, Critical thinking in psychology, Cambridge University Press, New York.

Hosseini, M \& Hosseini, SM 2011, '[Ethics of Critical thinking (Persian)]'. Journal of Philosophical Investigations, vol. 5, no. 8, pp. 1-13.

Lotfi, M, Hasankhani, H \& Mokhtari, M 2010, ' [Effect of compound education simulation and critical thinking strategies on clinical decision making in Surgical technologyist Students (Persian)]'. Nursing \& Midwifery Journal, vol. 5, no. 20, pp. 5-11.

Mazloomi, SS, Naderian, H \& Nahangi, H 2012, ‘Critical thinking ability and its associated factors among preclinical students in Yazd Shaheed Sadoughi University of Medical Sciences (Iran)', Medical Journal of the Islamic Republic of Iran, vol. 26, no. 2, pp. 5057.

Moattari, M, Abedi, H, Amini ,A \& Fathi, E 2002, '[Reflection perspectives of Tabriz Nursing Student (Persian)]', Iranian Journal of Medical Education, vol. 2, no. 3, pp. 40-47.

Nafeei, A 2007, '[Tabriz student critical thinking skills (Persian)]', Journal of Nursing and Midwifery, vol. 2, no. 6, pp. 52-67.

Neyestani, MR \& Emamverdi, D 2011, [Examine the role of critical thinking in social life (Persian)], Sadra Islamic philosophy institute, http://www.pac.org.ir/fa/?c=content\&id=171.

Paryad, E, Javadi, N, Atrkarroshan, Z, Fadakar, K \& Asiri S 2011, '[Relationship between Critical Thinking and Clinical Decision Making in Nursing Students (Persian)]', Iran Journal of Nursing, vol. 24, no. 73, pp. 63-71.

Sarhangi, F, Masomi, M, Ebadi, A, Mazhari, M, Rahmani, A, Raeisifar, A et al 2010, '[Comparing the effect of lecture- and concept mapping based learning on cognitive learning levels (Persian)]', Journal of Critical Care Nursing, vol. 3, no. 4, pp. 1-5. 
